\title{
Chemical characterization and assessment of antioxidant potentiality of Streptocaulon sylvestre Wight, an endangered plant of sub-Himalayan plains of West Bengal and Sikkim
}

\author{
Priyankar Dey ${ }^{1}$, Sandipan Ray², Mousumi Poddar Sarkar ${ }^{2}$ and Tapas Kumar Chaudhuri ${ }^{*}$
}

\begin{abstract}
Background: S. sylvestre Wright is an extremely rare plant, found only in the sub-Himalayan Terai region of West Bengal and neighboring Sikkim foot-hills. The plant has never been evaluated for any pharmaceutical properties. The phytochemical status of the plant is still unknown. Therefore, the aim of the study was to explore the antioxidant and free radical scavenging activities and analysis of bioactive compounds present in S. sylvestre.

Methods: S. sylvestre methanolic extract (SSME) was evaluated for different free radical scavenging activities such as hydroxyl radical, nitric oxide, singlet oxygen, hypochlorous acid, peroxynitrite, superoxide radical and hydrogen peroxide scavenging etc. Iron chelating capacity and inhibition of lipid peroxidation were studied in addition to the assessment of haemolytic activity and erythrocyte membrane stabilizing activity (EMSA). Chemical characterization of SSME were performed by high performance liquid chromatography (HPLC) and gas chromatography-mass spectrometry (GC-MS).

Results: The results indicate that SSME possess potent antioxidant activity with $\mathrm{IC}_{50}$ value of $113.06 \pm 5.67 \mu \mathrm{g} / \mathrm{ml}$, $63.93 \pm 4.16 \mathrm{\mu g} / \mathrm{ml}$ and $142.14 \pm 6.13 \mu \mathrm{g} / \mathrm{ml}$ for hydroxyl radical, superoxide radical and hypochlorous acid, respectively. HPLC analysis revealed presence of different phenolic secondary metabolites such as gallic acid, ferulic acid, p-coumaric acid, syringic acid, myricetin, quercetin etc. GC-MS analysis displayed the predominance of $Y$-sitosterol, vitamin $E$ and squalene in SSME.
\end{abstract}

Conclusion: The present study provides a convincing evidence that $S$. sylvestre not only possess potent antioxidant activity but also can be used as a source of natural bioactive phytochemicals in the future.

Keywords: Antioxidant, Flavonoid, Free radical, GC-MS, Haemolytic, HPLC, Iron chelation, Lipid peroxidation, Phenolic, Streptocaulon

\section{Background}

The genus Streptocaulon belonging to the family Apocynaceae (previously Asclepiadaceae) having extensive distribution in tropical Asia. Venter and Verhoeven described nine distinct species under the genus Streptocaulon [1]. However, according to 'The Plant List', 23 plants are enlisted under Streptocaulon with 6 accepted, 10 synonyms and 7 unresolved names [2] including $\mathrm{S}$.

\footnotetext{
* Correspondence: dr_tkc_nbu@rediffmail.com

${ }^{1}$ Cellular Immunology Laboratory, Department of Zoology, University of North Bengal, Siliguri 734013, West Bengal, India

Full list of author information is available at the end of the article
}

sylvestre Wight (Figure 1) which is presently under review by the 'World Checklist of Selected Plant Families' (WCSP). S. sylvestre is an extremely rare plant (Additional file 1). According to present literature survey, distribution of the plant is restricted only to very selective parts of the earth i.e. in the sub-Himalayan plains of West Bengal and foot-hills of Sikkim Himalaya in India [3,4]. The plant was initially collected by Hamilton (Ham. Herb. No. 763) in 1809 form Sannyasikata at Rajgunj block in Jalpaiguri district (West Bengal, India) and subsequently named by Wright in 1834 [3]. Presently the plant is only reported to grow in several patches in different open fields within the 


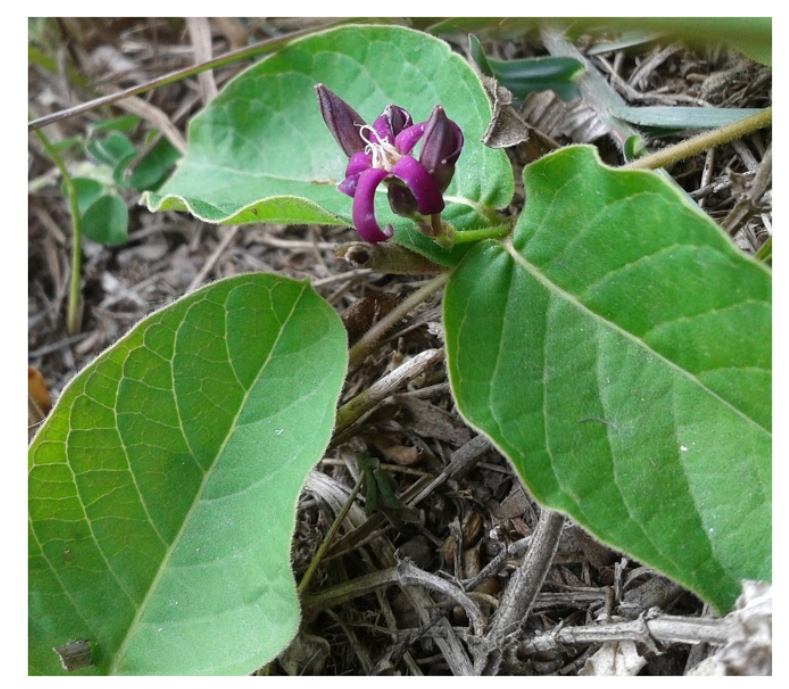

Figure 1 Picture of Streptocaulon sylvestre Wright. Picture was taken at the garden of Department of Zoology, University of North Bengal. campus of University of North Bengal (NBU) [3], including the garden of Department of Zoology. The University administration has very recently take a radical initiative for in situ conservation of the plant growing in several patches on a land near the Mathematics department of NBU and given a local name 'Uttara' to the plant. In addition, our lab has maintained and taking care of different patches of $S$. sylvestre growing in the garden our Zoology department. At present, best to our knowledge, NBU is the only place in entire world where the plant can be found growing in its natural habitat.

Very limited scientific information is available on this rare plant because of it's non-availability. PubMed search revealed no available information in the global database however, Google search resulted in around 2,640 hits, but most of them were actually hits on different plants of the same genus. Several studies have been conducted on the medicinal properties of other plants of the genus Streptocaulon. In vitro antioxidant activity of S. juventas and S. baummi were studied previously $[5,6]$. Various extracts and bioactive cardiac glycoside isolated from $S$. juventas displayed anti-proliferative activity against different cancer cell-lines [7-12]. Similarly, bioactive glycosides were isolated from S. griffithii which revealed potent anti-cancer properties [13-15]. Wessjohann and his group reported anti-cancer property of cardenolides isolated from S. tomentosum [16]. Unfortunately, no report is available either regarding the bioactivity of $S$. sylvestre or regarding its medicinal value in the ethnopharmacological literatures.

Pharmacological activities of S. sylvestre were evaluated by studying antioxidant and free radical scavenging activities in addition to assessment of iron chelation, haemolytic activity, inhibition of lipid peroxidation and erythrocyte membrane stabilizing activity (EMSA) in this first hand pilot study. Besides, chemical characterization were performed by spectrophotometric quantification of total phenolic and flavonoid contents and by chromatographic methods.

\section{Methods}

\section{Chemicals and solvents}

All the reagents were procured from HiMedia Laboratories Pvt. Ltd. (Mumbai, India), unless otherwise indicated. 6-hydroxy-2,5,7,8-tetramethychroman-2-carboxylic acid (Trolox) was obtained from Fluka, Switzerland. Hydrogen peroxide was obtained from SD fine-chem Ltd (Mumbai, India). HPLC standards were procured form Sigama Aldrich (USA) and ChromaDex (USA). HPLC grade solvents were obtained from Sisco Research Laboratories Pvt Ltd (India). Milli-Q ultrapure water from the departmental facility was used in all the experiments.

\section{Plant material}

S. sylvestre plant grows in different small patches in the ground. The plant was previously identified and authenticated by plant taxonomist Prof. A. P. Das of Dept. of Botany. Voucher specimen was also previously stored in the herbarium of NBU. Around $200 \mathrm{~g}$ whole plant including root, stem and leaves were collected from $25 \pm 2$ different patches from the garden of Dept. of Zoology, NBU (26⒋ $\left.35.3^{\prime \prime} \mathrm{N}, 88^{\circ} 21^{\prime} 08.4^{\prime \prime}\right)$. The sampling was performed in random in case of patch selection and also plant part (root, stem, root) selection. All the plant samples were collected in a single day (September 6th, 2014) and in a single sampling event.

\section{Sample preparation}

The fresh and disease free plant material was washed twice with double distilled water, shade dried at room temperature for 21 days and then grinded to powder. The powder (100 g) was mixed with 100\% methanol $(1000 \mathrm{ml})$ and kept in a shaking incubator $(160 \mathrm{rpm})$ for $18 \mathrm{~h}$ at $37^{\circ} \mathrm{C}$. Then the mixture was centrifuged at $5000 \mathrm{rpm}$ for 15 minutes. The pellet was resuspended in $100 \%$ methanol $(1000 \mathrm{ml})$ and kept overnight at the shaking incubator as previous. The supernatant liquid was collected from both the phases and filtered. The resultant filtrate was concentrated in a rotary evaporator under reduced pressure. The concentrated $S$. sylvestre methanolic extract (SSME) was lyophilized and stored at $-20^{\circ} \mathrm{C}$ until further use. The final yield was $6 \%$ of the initial powdered sample. 


\section{Collection of brain samples and blood}

Blood from Swiss albino mouse was collected in a EDTA containing tube by puncturing the heart under proper anesthesia. The blood samples were used for EMSA and haemolytic activity assay. Lipid peroxidation assay was performed using the brain of the same mouse. All the experiments were approved by the ethical committee of the Department of Zoology, NBU and performed in accordance with the legislation for the protection of animals used for scientific purposes.

\section{Trolox equivalent antioxidant capacity (TEAC)}

TEAC of SSME was assayed on the basis of the ability of SSME to scavenge ABTS ${ }^{\circ-}$ under a duration of $6 \mathrm{~min}$, which was compared to standard trolox [17]. The percentage inhibition of absorbance was calculated and plotted as a function of concentration of trolox and SSME to determine the TEAC. TEAC was calculated by dividing the gradient of plot for SSME by the gradient of plot for trolox.

\section{DPPH radical scavenging assay}

DPPH nitrogen radical scavenging assay was performed on the basis of reduction of 2,2-diphenyl-1-picrylhydrazyl (DPPH) recorded at $517 \mathrm{~nm}$ according to a standard method [18]. Ascorbic acid was used as standard.

\section{Hydroxyl radical scavenging assay}

Hydroxyl radical $\left(\mathrm{OH}^{*}\right)$ was generated through Fenton reaction of $\mathrm{Fe}^{3+}$-ascorbate-EDTA- $\mathrm{H}_{2} \mathrm{O}_{2}$ system and subsequently condensation of the degradation product of 2-deoxyribose with thiobarbituric acid (TBA) was estimated at $532 \mathrm{~nm}$ by the standard method of Elizabeth and Rao [19]. The classical $\mathrm{OH}^{*}$ scavenger mannitol was used as standard.

\section{Superoxide radical scavenging assay}

Superoxide radical $\left(\mathrm{O}_{2}^{--}\right)$, generated by the non-enzymatic combination of phenazine methosulfate (PMS) and reduced nicotinamide adenine dinucleotide (NADH), was measured by the reduction of nitro blue tetrazolium (NBT) to purple-colored formazan using a previously standardized method [18]. Quercetin was used as standard.

\section{Nitric oxide (NO) radical scavenging assay}

At physiological $\mathrm{pH}$, NO was generated through the reaction between aqueous sodium nitroprusside (SNP) and oxygen, which was quantified by the Griess Ilosvoy reaction [20]. The pink azo-dye generated due to diazotization of nitrite ions with sulphanilamide and subsequent coupling with $\mathrm{N}$-(1-naphthyl) ethylenediamine dihydrochloride (NED) was measured at $540 \mathrm{~nm}$ using Curcumin as standard.

\section{Hydrogen peroxide scavenging assay}

Hydrogen peroxide scavenging capacity of SSME was studied by FOX reagent method in which oxidation product of $\mathrm{Fe}^{2+}$ binds to xylenol orange. The absorbance was measured at $560 \mathrm{~nm}$ [21]. Sodium pyruvate was used as standard.

\section{Peroxynitrite scavenging activity}

Previously described method of Beckman et al. [22] was followed to generate peroxynitrite $\left(\mathrm{ONOO}^{-}\right)$. Further, Evans blue bleaching assay, as described by Bailly et al. [23], was followed to assay the $\mathrm{ONOO}^{-}$scavenging activity of SSME at $611 \mathrm{~nm}$. Gallic acid was used as standard.

\section{Singlet oxygen scavenging assay}

Singlet oxygen $\left({ }^{1} \mathrm{O}_{2}\right)$ was generated by the reaction of sodium hypochloride $(\mathrm{NaOCl})$ and $\mathrm{H}_{2} \mathrm{O}_{2}$, and the ${ }^{1} \mathrm{O}_{2}$ scavenging activity of SSME was measured by monitoring the bleaching of N,N-dimethyl-4-nitrosoaniline (RNO) at $440 \mathrm{~nm}$ following a previously standardized method [18]. Lipoic acid was used as standard.

\section{Hypochlorous acid scavenging assay}

Hypochlorous acid ( $\mathrm{HOCl}$ ) was freshly generated by a reaction between $\mathrm{NaOCl}$ and $\mathrm{H}_{2} \mathrm{SO}_{4}$ at $\mathrm{pH}$ 6.2. The $\mathrm{HOCl}$ scavenging activity of SSME was measured at $404 \mathrm{~nm}$ by monitoring the decrease in absorbance of catalase following the method of Aruoma and Halliwell [24]. Ascorbic acid was used as standard.

\section{Measurement of reducing power}

The reducing capacity of SSME was measured at $700 \mathrm{~nm}$ following a standard method [25] where higher absorbance represents higher reducing power. Ascorbic acid was used as standard.

\section{Lipid peroxidation inhibition assay}

Inhibition of lipid peroxidation capacity of SSME was assayed by studying the inhibition of $\mathrm{OH}^{-}$catalyzed malondialdehyde (MDA) production from the polyunsaturated fatty acid (PUFA) in the mice brain samples. The decrease in absorbance was measured at $532 \mathrm{~nm}$ and trolox was used as standard [26].

\section{$\mathrm{Fe}^{2+}$ chelation}

Iron chelation activity of SSME was evaluated by measuring the decrease of intensity of violet complex, generated by coupling of $\mathrm{Fe}^{2+}$ and ferrozine at $562 \mathrm{~nm}$ following the method described by Haro-Vicente et al. [27]. EDTA was used as standard.

\section{Total antioxidant activity (TAA)}

TAA was studied at $695 \mathrm{~nm}$ following the method of by Prieto et al. [28] observing the reduction of $\mathrm{Mo}^{6+}$ to $\mathrm{Mo}^{5+}$ by SSME. Ascorbic acid was used as standard. 


\section{Quantification of total phenolic and flavonoid content}

Total phenolic and flavonoid content of SSME was estimated at $725 \mathrm{~nm}$ and $510 \mathrm{~nm}$, respectively by the previously standardized methods [18]. The phenolic and flavonoid contents were calculated from gallic acid (GA; $\left.R^{2}=0.9708\right)$ and quercetin $\left(Q C ; R^{2}=0.9891\right)$ standard curve, respectively.

\section{Erythrocyte membrane stabilizing activity (EMSA)}

EMSA of SSME was assayed using a standard method of Navarro et al. [29]. Quercetin was taken as standard. The erythrocyte membrane stabilizing activity was measured by the following equation:

$$
\% \text { of protection }=(\mathrm{As} / \mathrm{Ab}) \times 100
$$

Where, As and Ab are the absorbance value of SSME/ standard and blank, respectively.

\section{In vitro haemolytic activity}

Haemolytic activity of SSME was measured using mice blood by the measurement of released haemoglobin at $540 \mathrm{~nm}$ following the method of Kalaivani et al. [30]. Triton-X100 (0.1\%) was used as standard.

\section{HPLC analysis}

SSME was subjected to Bligh and Dyer's method [31] to remove the lipid contents. The upper methanolic fraction was used in next steps for elimination of protein and for extraction of secondary metabolites. Chilled acetone was added to the methanolic fraction in the ratio of $4: 1(\mathrm{v} / \mathrm{v})$ and kept for $1 \mathrm{~h}$ at $-20^{\circ} \mathrm{C}$. The solution was then centrifuged twice for $15 \mathrm{~min}$. at $15,000 \times g$ $\left(4^{\circ} \mathrm{C}\right)$. The pellet containing protein was discarded and the supernatant was subjected to thin layer chromatography (TLC) on a silica gel plate using 10\% acetic acid in chloroform as solvent. The corresponding bands of phenolic, flavonoids and methylphenol were eluted by acetonitrile after detection with $20 \% \mathrm{w} / \mathrm{v}$ $\mathrm{Na}_{2} \mathrm{CO}_{3}$ and diluted Folin-Ciocaltaeu reagent (1:3). The solution was then analyzed using HPLC (Agilent, USA) having Zorbax SB-C18 column $(4.6 \times 150 \mathrm{~mm}$, 3.5 micron) and equipped with Diod Array Detector. Gradient concentration of mobile phase A - methanol $(\mathrm{M})$ and $\mathrm{B}$ - water $(\mathrm{W})$ with $0.02 \% \mathrm{H} 3 \mathrm{PO} 4$ were $25 \%$ A + 75\% B for 5 min, $30 \% \mathrm{~A}+70 \%$ for $10 \mathrm{~min}, 45 \% \mathrm{~A}+$ $55 \%$ for $30 \mathrm{~min}$ and $80 \% \mathrm{~A}+20 \% \mathrm{~B}$ for $45 \mathrm{~min}$. The injection volume was $20 \mu \mathrm{l}$ and the flow rate was kept at $0.4 \mathrm{ml} / \mathrm{min}$ in every cases. Analytes were scanned in $275 \mathrm{~nm}$. The peaks were identified by comparing the relative retention time (RRT), co-chromatography and spectral patterns obtained from the standards of phenolic acids, flavonoids and methylphenol with a concentration of $0.05 \mathrm{mg} / \mathrm{ml}$ and run under the same condition. The analytes were estimated following external method by calibrating against response factor obtained from the known amount of authentic compounds with proper validation criteria. The concentration of the analytes were expressed in $\mu \mathrm{g} / \mathrm{g}$ as calculated from the dry weight $(\mathrm{dw})$ of SSME initially measured for the extraction process.

\section{GC-MS analysis}

SSME was separately dissolved in $\mathrm{n}$-hexane and dichloromethane (DCM) and the mixtures were centrifuged thrice at $12000 \mathrm{rpm}$ for $15 \mathrm{~min}$. The two clear supernatant was used for GC-MS analysis for identification of different classes of phytochemicals. Agilent 5975C GC-MS system (Agilent Technologies, USA) attached with HP-5 ms Capillary Column (30 m $\times$ $0.25 \mathrm{~mm}$ i.d. $\times 0.25 \mu \mathrm{m}$ film thickness) and equipped with inert MSD triple axis mass detector conditioned at ion trap $200^{\circ} \mathrm{C}$, transfer line $280^{\circ} \mathrm{C}$, electron energy $70 \mathrm{eV}$ (vacuum pressure- 2.21e-0.5 torr) was used for analysis. The carrier gas was helium at a flow rate of $1 \mathrm{ml} / \mathrm{min} .2 \mu \mathrm{l}$ sample was injected in a splitless mode. The column temperature was set at $60^{\circ} \mathrm{C}$ for $1 \mathrm{~min}$. followed by $5^{\circ} \mathrm{C} / \mathrm{min}$ upto $250^{\circ} \mathrm{C}$. The major and essential compounds in SSME were identified by their retention times and mass fragmentation patterns using Agilent Chem Station integrator and the database of National Institute Standard and Technology (NIST) with a MS library version 2010 and by analyzing MS fragmentation patterns.

\section{Statistical analysis}

All qualitative data are reported as the mean \pm SD of six measurements. Statistical analysis was performed by paired t-tests using KyPlot version 2.0 beta 15 (32 bit). $\mathrm{P}<0.05$ was considered significant. Percentage of inhibition/scavenging was calculated by the formula $=$ $\frac{X 0-X 1}{X 0} \times 100$, where $\mathrm{X} 0$ was the absorbance of the control and X1 was the absorbance in the presence of the samples and standard. The half maximal inhibitory concentration $\left(\mathrm{IC}_{50}\right)$ values were calculated by the formula $Y=\frac{A 1}{X+A 1} \times 100$, where $\mathrm{A} 1=\mathrm{IC}_{50}, \mathrm{Y}=$ response $(Y=100 \%$ when $X=0), X=$ inhibitory concentration. GC-MS analysis for identification of phytocompounds was done from three biological replicates for confirmation.

\section{Results}

Antioxidant and free radical scavenging activity

Antioxidant and free radical scavenging capacities of SSME and corresponding standards are demonstrated in Figures 2, 3, 4, and 5. At $2 \mathrm{mg} / \mathrm{ml}$ concentration, the amount of inhibition of ABTS ${ }^{\circ}$ by trolox and SSME were $99.18 \pm 0.19 \%$ and $81.69 \pm 1.87 \%$, respectively 


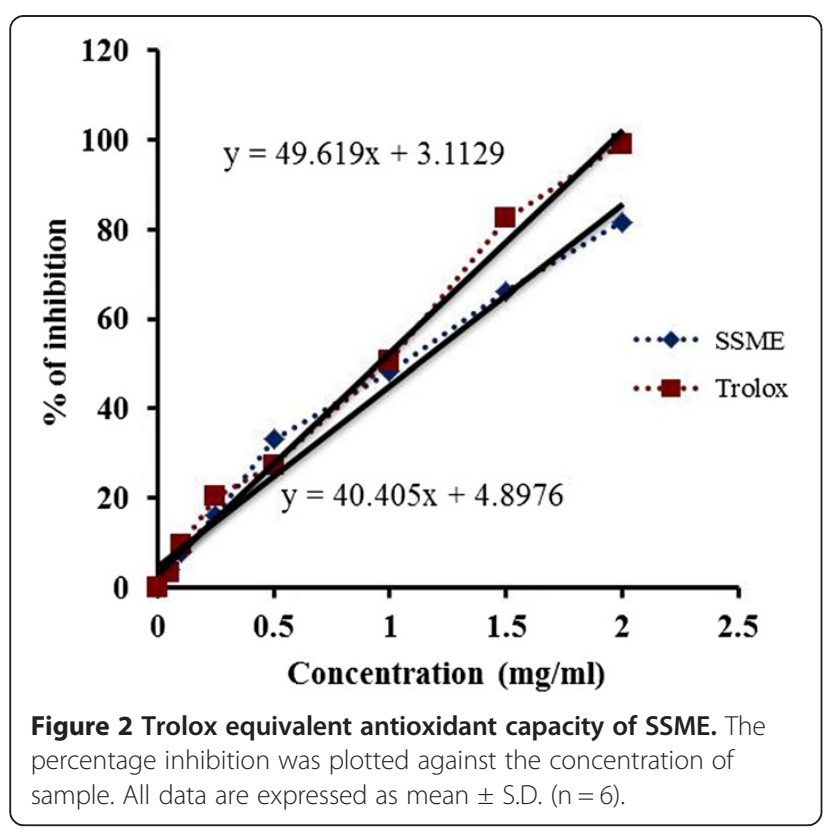

(Figure 2). The TEAC value of SSME was calculated to be $0.81 \pm 0.006$. The half maximal inhibitory concentration of SSME is significantly lower than the corresponding standards in $\mathrm{DPPH}, \mathrm{OH}^{*}, \mathrm{O}_{2}^{*-}$ and $\mathrm{HOCl}$ scavenging assays as displayed in Table 1.
Erythrocyte membrane stabilizing activity (EMSA)

Figure 6A displays erythrocyte membrane stabilizing activity of SSME in comparison to standard quercetin. At $200 \mu \mathrm{g} / \mathrm{ml}$, percentage of protection by SSME was $34.88 \pm 3.48 \%$ and quercetin was $68.50 \pm 3.45 \%$. The half maximal protection efficiency of SSME and quercetin were $341.62 \pm 25.73 \mu \mathrm{g} / \mathrm{ml}$ and $91.20 \pm 2.16 \mu \mathrm{g} / \mathrm{ml}$, respectively.

\section{Haemolytic activity}

The haemolytic activity of SSME is displayed in Figure 6B. At $100 \mu \mathrm{g} / \mathrm{ml}$, the haemolytic activity of SSME was $4.40 \pm 1.85 \%$ which significantly less than that of triton-X100 (85.63 $\pm 3.49 \%)$. The half maximal haemolytic concentration was calculated to be $2.37 \mathrm{mg} / \mathrm{ml}$.

\section{Phenolic and flavonoid content}

The total phenolic content of SSME was $0.79 \pm 0.02 \mathrm{mg} / \mathrm{ml}$ GA equivalent/ mg plant extract and flavonoid content was $0.55 \pm 0.04 \mathrm{mg} / \mathrm{ml}$ QC equivalent per/ mg plant extract.

\section{HPLC analysis}

HPLC analysis of SSME revealed the presence of different bioactive secondary metabolites as represented in Figure 7. Gallic acid (GA; $64 \pm 5.10 \mu \mathrm{g} / \mathrm{g} \mathrm{dw}$ ), 4-hydroxybenzoic acid (4HBA; $3.035 \pm 1.09 \mu \mathrm{g} / \mathrm{g} \mathrm{dw}$ ), vanillic acid (VA; $4.54 \pm$ $1.54 \mu \mathrm{g} / \mathrm{g} \mathrm{dw}$ ), syringic acid (SA; $16.70 \pm 3.15 \mu \mathrm{g} / \mathrm{g} \mathrm{dw}$ ),

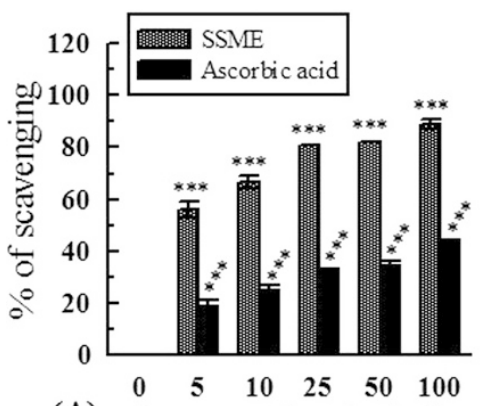

(A) Concentration $(\mu \mathrm{g} / \mathrm{ml})$

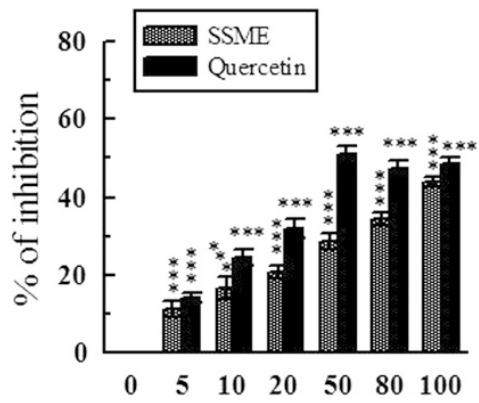

(C) Concentration $(\mu \mathrm{g} / \mathrm{ml})$
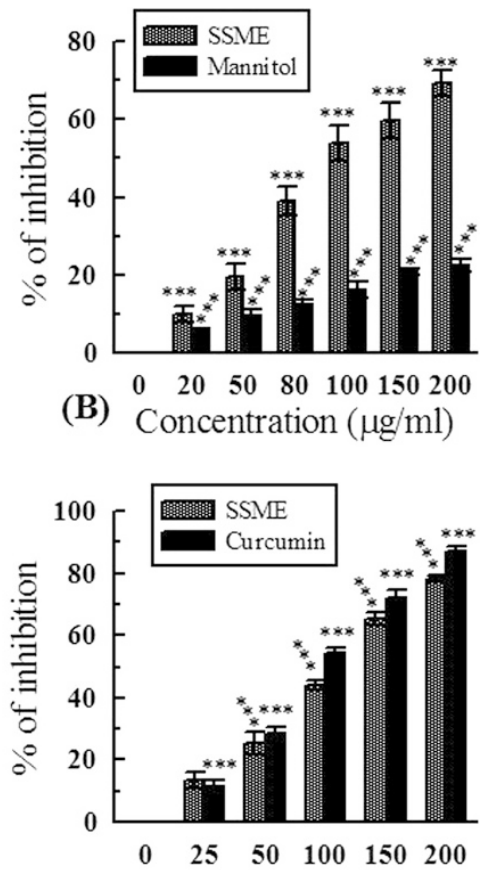

(D) Concentration $(\mu \mathrm{g} / \mathrm{ml})$

Figure 3 Antioxidant activity of S. sylvestre. (A) DPPH radical scavenging activity; (B) Hydroxyl radical scavenging activity; (C) Superoxide radical scavenging activity; (D) Nitric oxide scavenging activity. ${ }^{* *} \mathrm{p}<0.001 \mathrm{vs} 0 \mu \mathrm{g} / \mathrm{ml}$. 


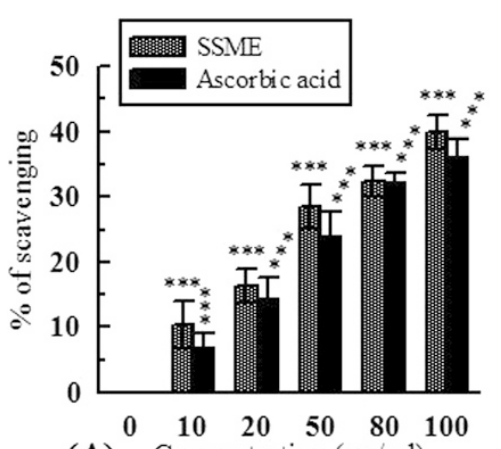

(A) Concentration $(\mu \mathrm{g} / \mathrm{ml})$

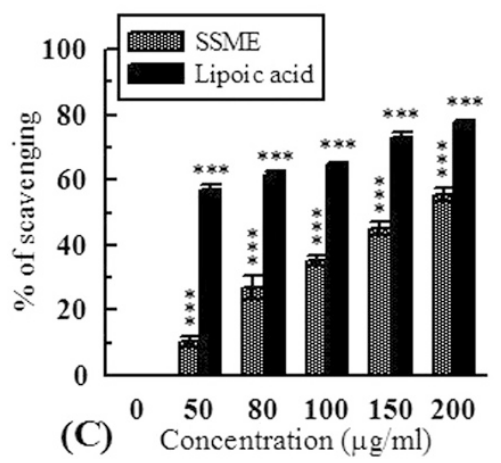

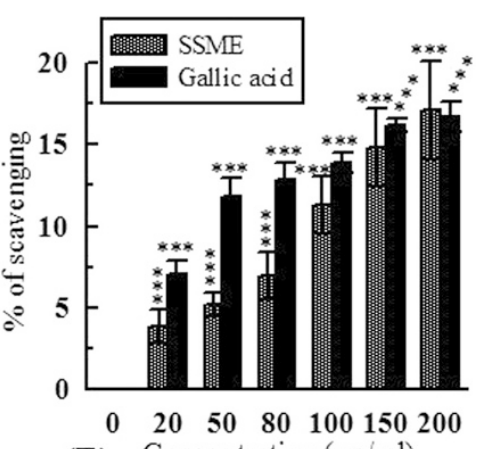

(B) Concentration $(\mu \mathrm{g} / \mathrm{ml})$

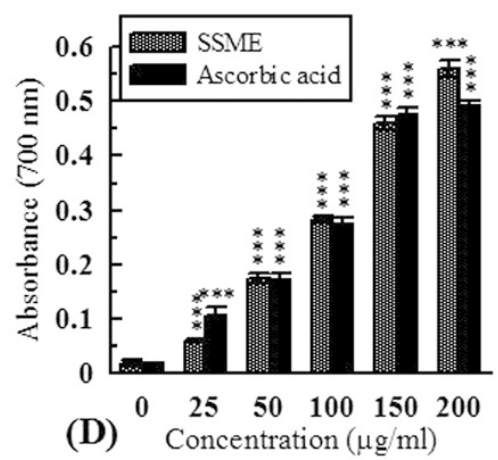

Figure 4 Antioxidant activity of S. sylvestre. (A) Hypochlorous acid scavenging activity; (B) Peroxynitrite scavenging activity; (C) Singlet oxygen scavenging activity; (D) Reducing power. ${ }^{* *} \mathrm{p}<0.001$ vs 0 rg/ml.

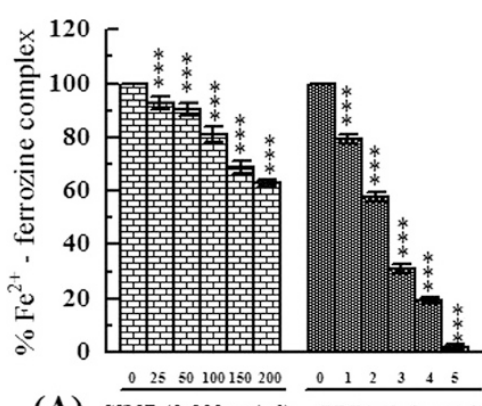

(A) $\operatorname{SSME}(0-200 \mu \mathrm{g} / \mathrm{ml}) \quad \frac{1}{\operatorname{EDTA}(0-6 \mu \mathrm{g} / \mathrm{ml})}$

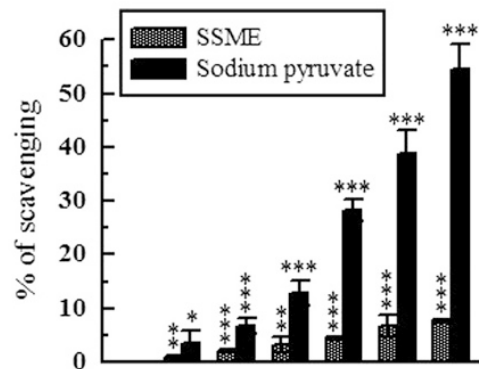

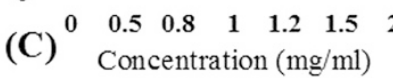

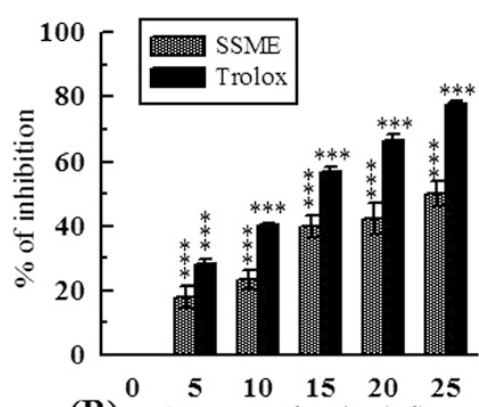

(B) ${ }^{0} \begin{array}{cccc}5 & 10 & 15 & 20 \\ \text { Concentration }(\mu \mathrm{g} / \mathrm{ml})\end{array}$

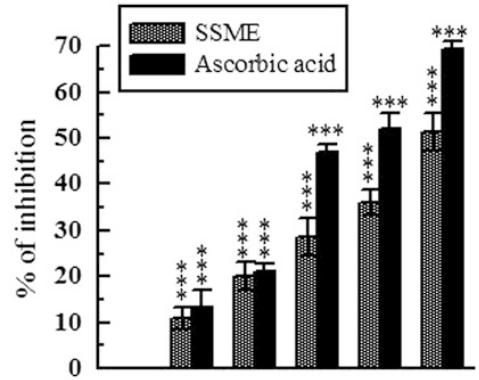

(D) ${ }^{0} \begin{array}{ccccc}50 & 80 & 100 & 150 & 200 \\ \text { Concentration } & (\mu \mathrm{g} / \mathrm{ml})\end{array}$

Figure 5 Antioxidant activity of S. sylvestre. (A) Iron chelation activity; (B) Inhibition of lipid peroxidation; (C) Hydrogen peroxide scavenging activity; (D) Total antioxidant activity. ${ }^{*} \mathrm{P}<0.01$ and ${ }^{* * *} \mathrm{P}<0.001 \mathrm{vs} 0 \mu \mathrm{g} / \mathrm{ml}$. 
Table 1 Half maximal inhibitory concentration $\left(\mathrm{IC}_{50}\right)$ of SSME and standards for different antioxidant and free radical scavenging assays

\begin{tabular}{lll}
\hline Parameters & SSME & Standard \\
\hline DPPH & $4.91 \pm 0.57^{* *}$ & $83.80 \pm 7.27$ (ascorbic acid) \\
Hydroxyl radical & $113.06 \pm 5.67^{* * *}$ & $589.06 \pm 46.57$ (mannitol) \\
Superoxide anion & $63.93 \pm 4.16^{* * *}$ & $121.41 \pm 5.72$ (quercetin) \\
Nitric oxide & $101.62 \pm 4.70^{* * *}$ & $80.46 \pm 3.10$ (curcumin) \\
Hydrogen peroxide & $25.48 \pm 3.13^{* * *}$ & $3.17 \pm 0.14$ (sodium pyruvate) \\
Peroxynitrite & $0.90 \pm 0.07^{* *}$ & $0.73 \pm 0.02$ (gallic acid) \\
Singlet oxygen & $196.36 \pm 12.58^{* * *}$ & $48.40 \pm 1.81$ (lipoic acid) \\
Hypochlorous acid & $142.14 \pm 6.13^{*}$ & $165.91 \pm 16.31$ (ascorbic acid) \\
Total antioxidant activity & $252.74 \pm 17.54^{* * *}$ & $150.01 \pm 7.31$ (ascorbic acid) \\
Iron chelation & $361.80 \pm 12.05^{* * *}$ & $1.45 \pm 0.04$ (EDTA) \\
Lipid peroxidation & $26.07 \pm 3.15^{* * *}$ & $11.11 \pm 0.22$ (trolox)
\end{tabular}

Units in $\mu \mathrm{g} / \mathrm{ml}$, except $\mathrm{H}_{2} \mathrm{O}_{2}$, peroxynitrite scavenging and iron chelating where the units are $\mathrm{mg} / \mathrm{ml}$. Data expressed as mean $\pm S . D(n=6) .{ }^{*} p<0.05$; ${ }^{* *} p<0.01 ; * * * 0.001$ vs standard.

p-coumaric acid (PCA; $9.81 \pm 3.35 \mu \mathrm{g} / \mathrm{g} \mathrm{dw}$ ), ferulic acid (FA; $7.98 \pm 1.48 \mu \mathrm{g} / \mathrm{g} \mathrm{dw}$ ), myricetin (MY; $14.14 \pm 4.99 \mu \mathrm{g} / \mathrm{g}$ $\mathrm{dw}$ ) and quercetin (QC; $2.30 \pm 0.66 \mu \mathrm{g} / \mathrm{g} \mathrm{dw}$ ) were the major phenolic acids and p-cresol (PC; $0.57 \pm 0.20 \mu \mathrm{g} / \mathrm{g} \mathrm{dw}$ ) was the soul alcohol identified.

\section{GC-MS analysis}

The results of GC-MS analysis is displayed in Figure 8 and Table 2. SSME revealed to contain various bioactive constituents of different chemical nature among which $\gamma$-Sitosterol, vitamin $\mathrm{E}$ and squalene were predominantly present.

\section{Discussion}

Natural antioxidant and free radical scavengers are the current focus in nutrition and health supplements besides most plants and polyherbal formulations of the traditional medicinal system are found to possess potent antioxidant capacities [32]. In recent years, the phrase 'oxidative stress' has become a potential concern in medicine which is reflected by the fact that the antioxidant related publications has nearly quadrupled in the past decade [33]. Oxidative stress, which is primarily generated due to the imbalance between reactive oxygen species (ROS) and antioxidative protection, going in favor of the former, is responsible for most of the major diseases. In addition to oxidation of polyenoic fatty acid rich foods, adverse environmental conditions such as pollution and UV radiation generates a plethora of free radicals which eventually mediates the degradation of cellular biomolecules.

Reducing power can be attributed to the anti-ROS activity as oxidation is the predominant mechanism behind free radical medicated damage even though a potent antioxidant should possess individual free radical scavenging properties besides potentials to chelate metals and inhibit lipid peroxidation [34]. TEAC and DPPH assay are the two most commonly used electron transfer methods for the assessment of antioxidant capacities of natural products. The concentration of test material giving same percentage of inhibition of ABTS $^{--}$compared to the same of trolox is regarded as TEAC. The ABTS ${ }^{--}$scavenging capacity of SSME was compared to that of trolox which demonstrated convincing TEAC value $(0.81 \pm 0.006)$. Similarly, DPPH which is a stable organic nitrogenous radical, [33] was scavenged by SSME at very low concentration. The DPPH scavenging activity of SSME was in fact higher than that of ascorbic acid.

Though short lived and low in concentration, hydroxyl radical $\left(\mathrm{OH}^{*}\right)$ is an extremely harmful ROS with tremendous potentiality to damage biomolecules [33]. $\mathrm{OH}^{*}$ is commonly generated through the Fenton reaction between $\mathrm{Fe}^{2+}$ and $\mathrm{H}_{2} \mathrm{O}_{2}$ [35]. On the contrary, metal chelators may also contribute to the reduction of $\mathrm{OH}^{*}$ by means of conversion of $\mathrm{Fe}^{2+}$ to $\mathrm{Fe}^{3+}$ and thus, hindering the Fenton reaction. Besides, breakdown of $\mathrm{H}_{2} \mathrm{O}_{2}$ into

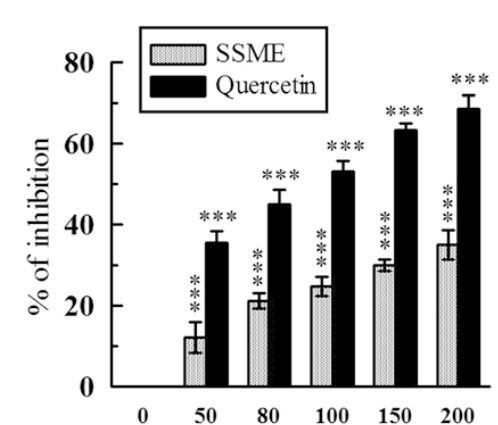

(A) Concentration $(\mu \mathrm{g} / \mathrm{ml})$

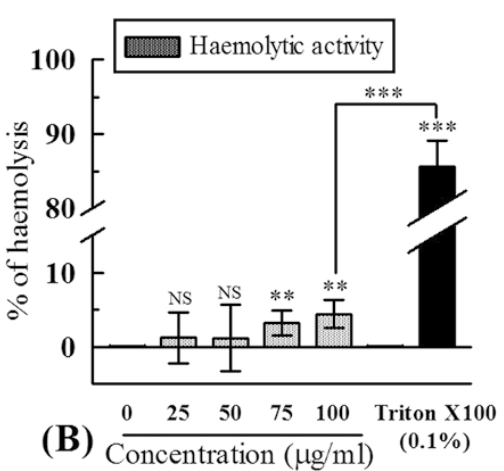

(B) $\frac{25 \quad 50 \quad 75}{\text { Concentration }(\mu \mathrm{g} / \mathrm{ml})}(0.1 \%)$

Figure 6 Bio-activities of SSME. (A) Erythrocyte membrane stabilizing activity; (B) Haemolytic activity. ${ }^{\text {NS }} \mathrm{P}>0.05$, ${ }^{* *} \mathrm{P}<0.01 \mathrm{and}{ }^{* * *} \mathrm{p}<0.001 \mathrm{vs} 0 \mu \mathrm{gg} / \mathrm{ml}$. 


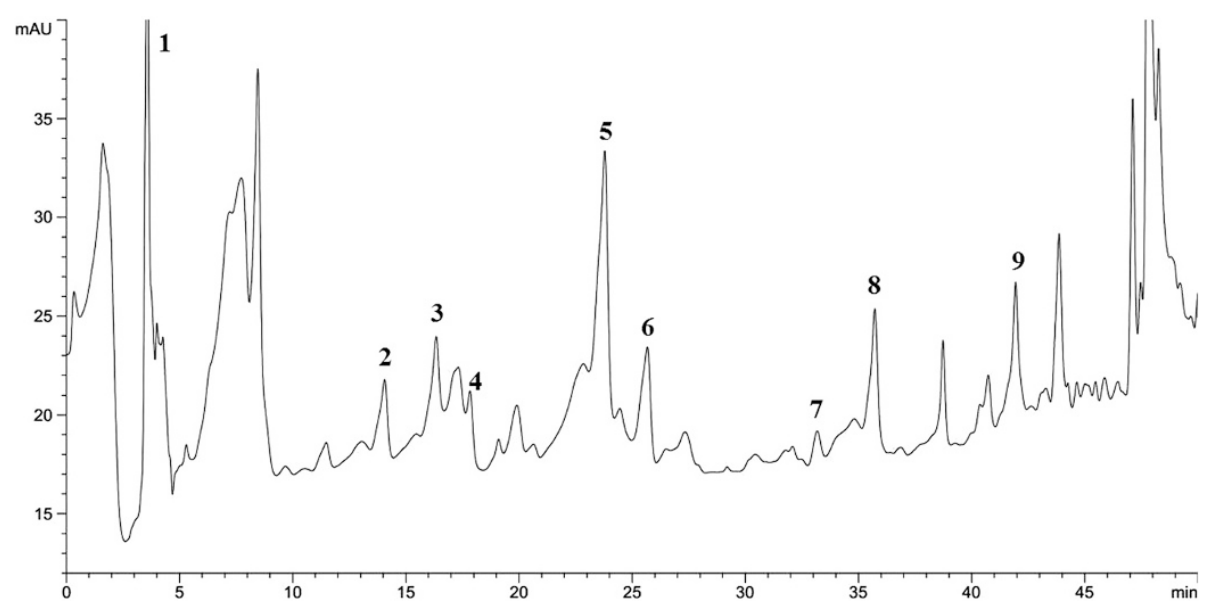

Figure 7 HPLC analysis of SSME. Identified compounds at $275 \mathrm{~nm}$ were (1) gallic acid, (2) 4-hydroxybenzoic acid, (3) vanillic acid, (4) syringic acid, (5) p-coumaric acid, (6) ferulic acid, (7) p-cresol, (8) myricetin, (9) quercetin.

$\mathrm{O}_{2}$ and $\mathrm{H}_{2} \mathrm{O}$ may also prevent $\mathrm{OH}^{*}$ formation [33]. $\mathrm{H}_{2} \mathrm{O}_{2}$ being a potent oxidizing agent by itself can affect cellular enzymes by oxidation of essential thiol $(-\mathrm{SH})$ groups [19]. Excess iron $\left(\mathrm{Fe}^{2+}\right)$ may further catalyse superoxide anion $\left(\mathrm{O}^{\cdot 2-}\right)$ mediated Haber-Weiss reaction to generate $\mathrm{OH}^{*}$ which ultimately results in lipid peroxidation. Highly toxic superoxide anion $\left(\mathrm{O}^{\cdot 2-}\right)$ is primarily generated from the mitochondrial respiration and its spontaneous dismutation may initiates lipid peroxidation by generation of singlet oxygen $\left({ }^{1} \mathrm{O}_{2}\right)$ [36]. ${ }^{1} \mathrm{O}_{2}$ on the other hand, is responsible for UV dependent skin damage and it initiates cardiovascular disorders by oxidation of LDL cholesterol. Various inflammatory conditions and carcinomas are associated with the binary molecule $\mathrm{NO}$ which itself couples with $\mathrm{O}^{\cdot 2-}$ to generate peroxynitrite $\left(\mathrm{ONOO}^{-}\right)$[33]. $\mathrm{ONOO}^{-}$and its protonated more reactive form $\mathrm{ONOOH}$ often results in nitration or hydroxylation of aromatic compounds and forms abduct with $\mathrm{CO}_{2}$ which in turn responsible for oxidative damage of proteins [36,37]. Myeloperoxidasemediated peroxidation of chloride in neutrophils gives rise to hypochlorous acid which mediates irreversible oxidation to cellular components [38]. Furthermore, various ROS such as $\mathrm{OH}^{*}$ and $\mathrm{H}_{2} \mathrm{O}_{2}$ initiates a selfpropagating chain reaction by attacking PUFA and thus, cause lipid peroxidation, responsible for pathogenesis of various diseases [39].

Previously Nguyen and Eun [5] studied the antioxidant capacity of different solvent extracts of Streptocaulon juventas, among which the aqueous extract demonstrated DPPH radical scavenging activity of $44.07 \pm 0.07 \%$ (DPPH: extract $=1: 3, \mathrm{v} / \mathrm{v})$ besides potent reducing power $\left(\mathrm{IC}_{50}\right.$ $0.85 \pm 0.02 \mathrm{mg} / \mathrm{ml}$ ). The iron chelation capacity was higher in methanolic extract with an $\mathrm{IC}_{50}$ value of $1.67 \pm$ $0.04 \mathrm{mg} / \mathrm{ml}$. In addition, the acetone and aqueous extracts respectively contained highest phenolic $(93.22 \pm 0.10 \mathrm{mg}$ GA equivalent/g extract) and flavonoid $(58.09 \pm 0.14 \mathrm{mg}$ QC equivalent per g extract). On the other hand, antioxidant property of Streptocaulon boumi was evaluated using a modified DPPH assay which demonstrated $-4.3 \%$ DPPH scavenging activity compared to GA [6]. In the present study SSME was evaluated for its antioxidant and free radical scavenging potentials through different antioxidant assays. SSME has demonstrated excellent $\mathrm{OH}^{*}, \mathrm{O}_{2}{ }^{-*}$ and $\mathrm{HOCl}$ scavenging activity, better than the respective standards. Besides, though SSME failed to display a convincing $\mathrm{H}_{2} \mathrm{O}_{2}$ activity, its iron chelation capacity was potent enough which may inhibit $\mathrm{OH}^{*}$ generation by inhibiting catalysis of Fenton reaction.

The erythrocyte ghost is extremely susceptible to oxidative damage affecting the deformability, aggregability of the cells. External superoxide radical $\left(\mathrm{O}_{2}{ }^{--}\right)$mediated attack gives rise to change in the dynamics of blood flow [40]. Erythrocyte membrane degradation in sickle condition is also governed by ROS mediated attack [41]. In such conditions the production of $\mathrm{O}_{2}{ }^{\circ-}, \mathrm{OH}^{*}$ and peroxide are elevated by two fold, thus requiring protection of the membrane from free radicals. In EMSA, haemolysis of erythrocytes was induced by generation of $\mathrm{O}_{2}{ }^{\cdot-}$ through autoxidation of riboflavin in presence of light. SSME displayed excellent membrane stabilizing capacity by inhibition of superoxide radical. Besides it has also displayed in vitro $\mathrm{O}_{2}{ }^{--}$scavenging activity which may further be an aid in erythrocyte membrane protection.

Haemolytic activity is one of the parameters of cytotoxicity by natural compounds. Certain ingredients in dietary supplements often contain varying amount of haemolytic activity such as saponins from alfalfa [42] results in release of haemoglobin due to irreversible damage of erythrocyte membrane. Winter (1994) described 


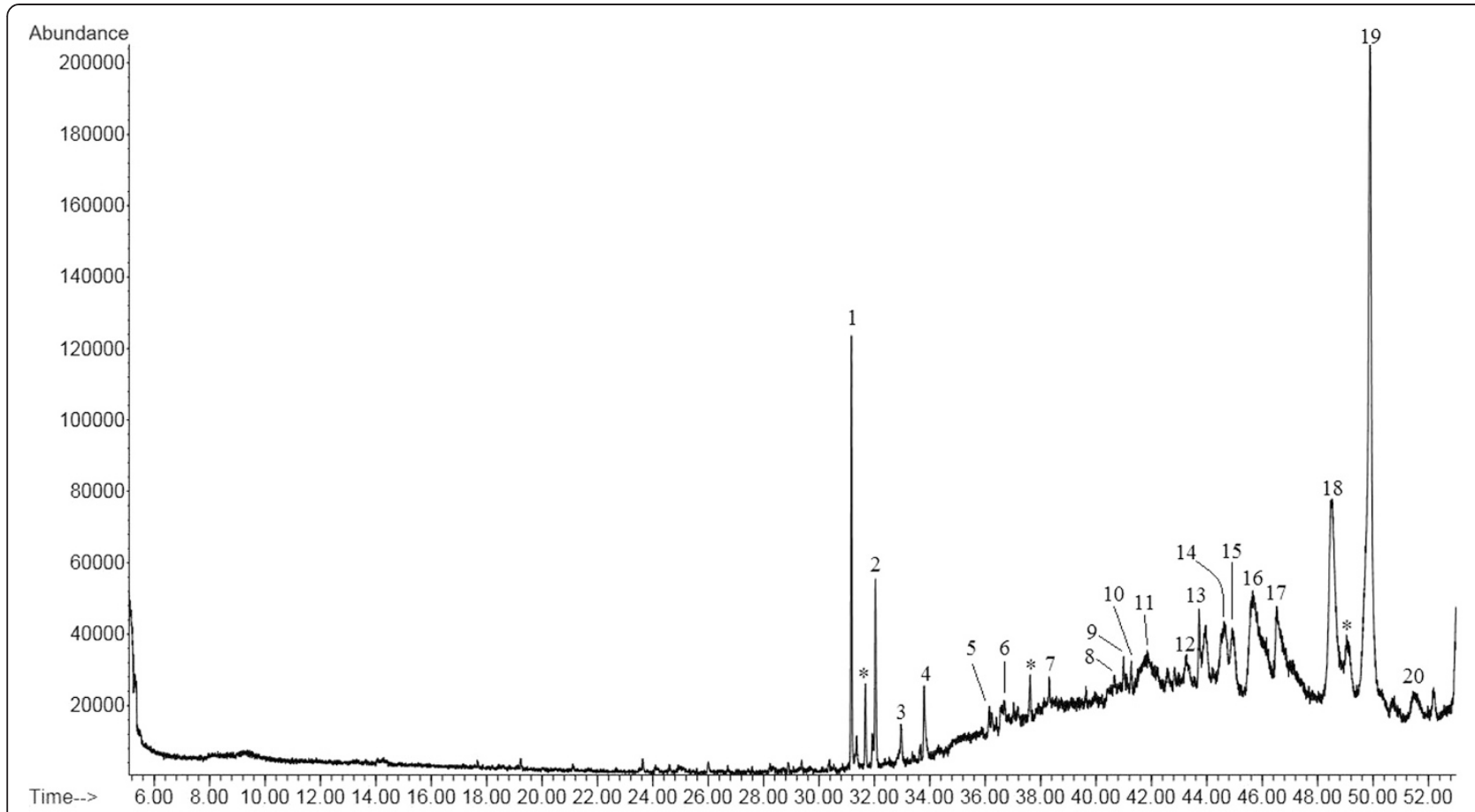

(A)

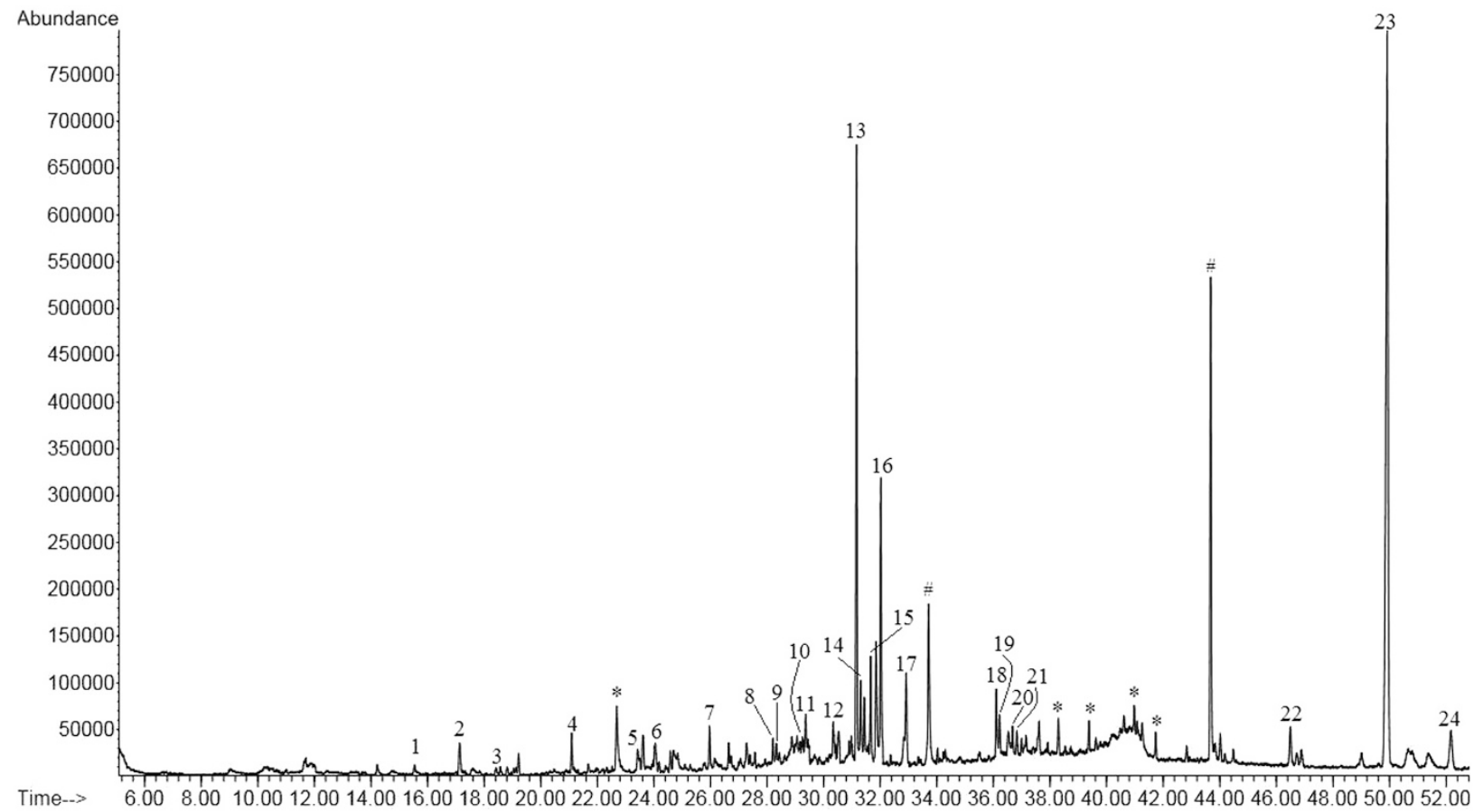

(B)

Figure 8 GC-MS identification of chemical fingerprint of SSME. (A) SSME dichloromethane fraction. (B) SSME $n$-hexane fraction. * = column component/ repeat compound/ unidentified compound. ${ }^{\#}=$ phthalate compound.

the process of saponin induced haemolysis mediated by increase of water carriage by aquaporins [43]. At the highest dose even though compared to control SSME displayed statistically significant $(\mathrm{P}<0.01)$ Haemolytic activity, but considering such high $\mathrm{HC}_{50}$ value the activity may be considered negligible. Besides, the haemolytic 
Table 2 List of phytocompounds identified by GCMS analysis which corresponds to Figure 8

SSME dichloromethane fraction (Figure 8A)

\begin{tabular}{|c|c|c|c|}
\hline SL no. & Compound Name & Retention time (RT) & Relative abundance (\%) \\
\hline 1 & Bicyclo [3.1.1] heptane, 2,6,6-trimethyl-, (1a,23,5a) & 31.165 & 4.17 \\
\hline 2 & 3,7,11,15-Tetramethyl-2-hexadecen-1-ol & 32.035 & 2.13 \\
\hline 3 & Hexadecanoic acid, methyl ester & 32.960 & 1.01 \\
\hline 4 & 1,2-Benzenedicarboxylic acid, butyl octyl ester & 33.799 & 1.30 \\
\hline 5 & 12-Methyl-E,E-2,13-octadecadien-1-ol & 36.144 & 0.37 \\
\hline 6 & Methyl trans-9-(2-butylcyclopentyl) nonanoate & 36.707 & 1.23 \\
\hline 7 & 18-Nonadecen-1-ol & 38.309 & 0.53 \\
\hline 8 & Tetradecanal & 40.992 & 0.54 \\
\hline 9 & Oxalic acid, cyclobutyl pentadecyl ester & 41.268 & 0.40 \\
\hline 10 & Hexadecanal & 41.568 & 0.67 \\
\hline 11 & Octadecenoic acid (Z)-, 2,3-bis (acetyloxy) propyl ester & 41.837 & 2.13 \\
\hline 12 & Trichloroacetic acid, 3-tetradecyl ester & 43.269 & 1.48 \\
\hline 13 & Stigmasteryl tosylate & 43.957 & 2.41 \\
\hline 14 & Stigmastan-6,22-dien, 3,5-dedihydr o- & 44.658 & 3.99 \\
\hline 15 & Diazoprogesterone & 44.914 & 2.43 \\
\hline 16 & $\gamma$-Sitosterol & 45.659 & 11.95 \\
\hline 17 & Cholestane, 4,5-epoxy-,(4a, 5a)- & 46.522 & 10.24 \\
\hline 18 & Vitamin $\mathrm{E}$ & 48.517 & 13.74 \\
\hline 19 & Squalene & 49.894 & 27.34 \\
\hline 20 & 17-Pentatriacontene & 51.445 & 2.03 \\
\hline
\end{tabular}

\section{SSME $\mathbf{n}$-hexane fraction (Figure $8 \mathrm{~B}$ )}

SL no.

\section{Compound Name}

Heptane, 2,6-dimethyl-

Benzene, 1,3-bis(1,1-dimethylethyl)-

Oxalic acid, isobutyl nonyl ester

Tetradecane

Trans- $\beta$-Ionone

Phenol, 2,4-bis(1,1-dimethylethyl)

Hexadecane

Heptadecane

Hexadecane, 2,6,11,15-tetramethyl-

1-Decanol, 2-hexyl-

Hentriacontane

Octadecane

Bicyclo[3.1.1]heptane, 2,6,6-trimethyl-, (1a,2 $3,5 a)$

2-Pentadecanone, 6,10,14-trimethyl

1,4-Eicosadiene

Cyclohexanol, 1-ethynyl-

Hexadecanoic acid, methyl ester

9,12-Octadecadienoic acid, methyl ester, (E,E)-

9-Octadecenoic acid, methyl ester,(E)-

Phytol

Heptadecanoic acid, 15-methyl-, methyl ester
Retention time (RT)

15.540

17.135

18.423

21.094

23.427

24.047

25.967

28.206

28.332

29.245

29.364

30.340

31.159

31.309

31.659

32.022

32.917

36.107

36.213

36.526

36.676
Relative abundance (\%)

0.29

0.60

0.15

0.53

0.59

0.71

0.62

0.48

0.51

0.63

1.42

1.05

6.64

1.46

1.94

3.99

1.96

1.14

1.25

0.89

0.71 
Table 2 List of phytocompounds identified by GCMS analysis which corresponds to Figure 8 (Continued)

\begin{tabular}{llrr}
\hline 22 & Tritetracontane & 46.497 & 0.75 \\
23 & Squalene & 49.919 & 16.10 \\
24 & 2-methyloctacosane & 52.171 & 1.14 \\
\hline
\end{tabular}

activity of SSME was significantly $(\mathrm{P}<0.001)$ less than that of the standard triton-X100.

Today, the inventory of antioxidative phytochemicals chiefly consist of phenolic and flavonoid compounds which have also demonstrated a vast range of bioactivities. Antioxidant properties of phenolics are governed by their ability to be oxidized apart from their capacity to turn hydroxyl radicals into harmless $\mathrm{OH}^{*}$ derivative through incorporation into double bonds. The HPLC analysis revealed different bioactive secondary metabolites which have already been recognized for their pharmacological properties. GA [44], VA [45], FA [46], PCA [47], MY and QC [48] possess potent antioxidant capacities. Liu et al. [49] previously isolated FA, SA and $\beta$-sitosterol from $S$. juventas. In addition, GC-MS analysis revealed the presence of very high quantity of $\gamma$-sitosterol, vitamin E and squalene. Sitosterol possess anti-diabetic and free radical scavenging capacity [50]. Squalene and vitamin E are also predominant among the phytoconstituents of some other plants of the same family (Apocynaceae) [51]. Apart from its active role in nutrition, vitamin $\mathrm{E}$ is a natural antioxidant. Further, squalene is also a natural antioxidant found in majority of plants [52]. Therefore, the presence of these bioactive phytochemicals in S. sylvestre is the responsible factors behind the potent antioxidant activity of SSME.

\section{Conclusion}

The current study reports the first ever pharmacological evaluation of a rare plant S. sylvestre in addition to elucidation of its chemical fingerprints. In recent years, free radical mediated oxidative stress has emerged as the corner-stone of the pathogenesis of several harmful diseases [18]. NO, $\mathrm{ONOO}^{-}, \mathrm{H}_{2} \mathrm{O}_{2}, \mathrm{O}_{2}^{--}$are $\mathrm{OH}^{*}$ are essential parts of immune reactions in phagocytes during chronic pro-inflammatory response, causing tissue damage. Moreover, progression of diabetic complications [53] and hepatotoxicity due to idiosyncratic drug reaction [54] are primarily governed by free radicals, reactive metabolic intermediates and subsequent depletion in antioxidative protection. Therefore, the antioxidant capacity of $S$. sylvestre may prove beneficial in amelioration of such conditions. S. sylvestre also holds tremendous potential for its therapeutic efficiency in future due to presence of several bioactive constituents. However, at present awareness of the existence of the plant and plant tissue culture based methods are required for further propagation of this rare plant in different parts of the world.

\section{Additional file}

Additional file 1: Supplementary data.

\section{Competing interests}

The authors declare that they have no competing interests.

\section{Authors' contributions}

PD performed all the anti-oxidant experiments except TEAC, performed GC-MS analysis, statistical analysis and drafted the manuscript. SR performed TEAC and HPLC analysis. MPS supervised the phytochemical analysis and participated in drafting of the manuscript. TKC designed, coordinated and supervised the study and drafted the manuscript. All authors read and approved the final manuscript.

\section{Acknowledgement}

The authors are grateful to Prof. A.P. Das of Dept. of Botany, NBU for identifying this rare plant and taking foremost initiative in the conservation of the plant. We would like to thank the authority of NBU for taking active steps for in situ conservation of S. sylvestre. We are thankful to Somit Dutta and Bijoy Mahanta of Cellular Immunology Laboratory, NBU for collection of the plant material. DST-FIST programme of Govt. of India for providing instrumental facility at the Dept. of Botany, University of Calcutta is thankfully acknowledged.

\section{Author details}

${ }^{1}$ Cellular Immunology Laboratory, Department of Zoology, University of North Bengal, Siliguri 734013, West Bengal, India. ${ }^{2}$ Chemical Signal and Lipidomics Laboratory, Department of Botany, University of Calcutta, Kolkata 700019, India.

Received: 26 November 2014 Accepted: 23 March 2015

Published online: 08 April 2015

\section{References}

1. Venter HJT, Verhoeven RL. Diversity and relationships within the Periplocoideae (Apocynaceae). Ann Mo Bot Gard. 2001;88:550-68.

2. The plant list [http://www.theplantlist.org/tpl1.1/search?q=Streptocaulon] Accessed: 27.06.2014.

3. Das AP. Rediscovery of Streptocaulon sylvestre Wight-an endangered and little known endemic plant of Eastern India. J Bombay Nat Hist Soc. 1996:93:320-2

4. Sidney NC. A taxonomic revision of Finlaysonia and Streptocaulon (Periplocoideae; Apocynaceae). South Africa: Department of Plant Sciences (Botany), University of the Free State; 2012. MSc thesis.

5. Nguyen QV, Eun JB. Antioxidant activity of solvent extracts from Vietnamese medicinal plants. J Med Plant Res. 2011;5:2798-811.

6. Jacinto SD, Ramos EF, Siguan APT, Canoy RJC. Determining the Antioxidant Property of Plant Extracts: A Laboratory Exercise. Asian J Biol Edu. 2011;5:22-5.

7. Ueda JY, Tezuka Y, Banskota AH, Le Tran Q, Tran QK, Harimaya Y, et al. Antiproliferative activity of Vietnamese medicinal plants. Biol Pharm Bull. 2002;25:753-60.

8. Han N, Yang J, Li L, Xiao B, Sha S, Tran L, et al. Inhibitory activity of a phytochemically characterized fraction from Streptocaulon juventas on lung cancer in nude mice. Planta Med. 2010;76:561-5. 
9. Ueda JY, Tezuka Y, Banskota AH, Tran QL, Tran QK, Saiki I, et al. Constituents of the Vietnamese medicinal plant Streptocaulon juventas and their antiproliferative activity against the human HT-1080 fibrosarcoma cell line. J Nat Prod. 2003;66:1427-33.

10. Xue R, Han N, Ye C, Wang HB, Yin J. Cardenolide glycosides from root of Streptocaulon juventas. Phytochemistry. 2013;88:105-11.

11. Xue R, Han N, Sakurai H, Saiki I, Ye C, Yin J. Cytotoxic cardiac glycosides from the roots of Streptocaulon juventas. Planta Med. 2013;79:157-62.

12. Ueda JY, Tezuka Y, Banskota AH, Tran QL, Tran QK, Saiki I, et al. Antiproliferative activity of cardenolides isolated from Streptocaulon juventas. Biol Pharm Bull. 2003;26:1431-5.

13. Zhang L, Xu LZ, Yang SL. Two new cardenolides from the roots of Streptocaulon griffithii. J Asian Nat Prod Res. 2006:8:613-7.

14. Zhang XH, Zhu HL, Yu Q, Xuan LJ. Cytotoxic cardenolides from Streptocaulon griffithii. Chem Biodivers. 2007;4:998-1002.

15. Luan LJ, Wang YF, Zhang L, Wu YJ. Effect of griffithin on anticancer activity and apoptosis of cancer cells in vitro. Acta Pharm Sinic. 2007;42:104-7.

16. Rashan L, Franke K, Khine MM, Kelter G, Fiebig HH, Neumann J, et al. Characterization of the anticancer properties of monoglycosidic cardenolides isolated from Nerium oleander and Streptocaulon tomentosum. J Ethnopharmacol. 2011;134:781-8.

17. Re R, Pellegrini N, Proteggente A, Pannala A, Yang M, Rice-Evans C. Antioxidant activity applying an improved ABTS radical cation decolorization assay. Free Radical Biol Med. 1999;26:1231-7.

18. Dey P, Chaudhuri D, Chaudhuri TK, Mandal N. Comparative assessment of the antioxidant activity and free radical scavenging potential of different parts of Nerium indicum. Int J Phytomed. 2012;4:54-69.

19. Kunchandy E, Rao MNA. Oxygen radical scavenging activity of curcumin. Int J Pharmaceut. 1990;58:237-40.

20. Garratt DC. The quantitative analysis of drugs. Japan: Chapman and Hall Ltd.; 1964.

21. Long LH, Evans PJ, Halliwell B. Hydrogen peroxide in human urine: implications for antioxidant defense and redox regulation. Biochem Biophys Res Commun. 1999;262:605-9.

22. Beckman JS, Chen H, Ischiropulos H, Crow JP. Oxidative chemistry of peroxynitrite. Methods Enzymol. 1994;233:229-40.

23. Bailly F, Zoete V, Vamecq J, Catteu JP, Bernier JL. Antioxidant actions of ovothiol-derived 4-mercaptoimidazoles: glutathione peroxidase activity and protection against peroxynitrite-induced damage. FEBS Lett. 2000;486:19-22.

24. Aruoma Ol, Halliwell B. Action of hypochlorous acid on the antioxidant protective enzymes superoxide dismutase, catalase and glutathione peroxidase. Biochem J. 1987;248:973-6.

25. Oyaizu M. Studies on products of browning reactions: Antioxidant activities of products of browning reaction prepared from glucose amine. Jap J Nutr. 1986;44:307-15.

26. Kizil G, Kizil M, Yavuz M, Emen S, Hakimoglu F. Antioxidant activities of ethanol extracts of Hypericum triquetrifolium and Hypericum scabroides. Pharm Biol. 2008:46:231-42.

27. Haro-Vicente JF, Martinez-Gracia C, Ros G. Optimization of in vitro measurement of available iron from different fortificants in citric fruit juices. Food Chem. 2006:98:639-48.

28. Prieto P, Pineda M, Aguilar M. Spectrophotometric quantitation of antioxidant capacity through the formation of a phosphomolybdenum complex: specific application to the determination of vitamin E. Anal Biochem. 1999;269:337-41.

29. Concepcion Navarro M, Pilar Montilla M, Martin A, Jimenez J, Pilar Utrilla M. Free radical scavenger and antihepatotoxic activity of Rosmarinus tomentosus. Planta Med. 1993;59:312-4.

30. Kalaivani T, Rajasekaran C, Suthindhiran K, Mathew L. Free radical scavenging, cytotoxic, and Haemolytic activities of an active antioxidant compound ethyl gallate from leaves of Acacia nilotica (L.) Wild. Ex. Delile subsp. indica (Benth.) Brenan. J Food Sci. 2011;76:T144-9.

31. Bligh EG, Dyer WJ. A rapid method for total lipid extraction and purification. Can J Biochem Physiol. 1959;37:911-7.

32. Scartezzini P, Speroni E. Review on some plants of Indian traditional medicine with antioxidant activity. J Ethnopharmacol. 2000;71:23-43.

33. Huang D, Ou B, Prio RL. The chemistry behind antioxidant capacity assays. J Agric Food Chem. 2005;53:1841-56.

34. Pokorny J. Are natural antioxidants better-and safer-than synthetic antioxidants. Eur J Lipid Sci Technol. 2007;109:629-42.
35. Wanasundara PKJPD, Shahidi F. Antioxidants: Science, Technology, and applications. In: Shahidi F, editor. Bailey's Industrial Oil and Fat Products. Volume 6. USA: John Wiley \& Sons, Inc; 1995

36. Muller FL, Lustgarten MS, Jang Y, Richardson A, Van Remmen H. Trends in oxidative aging theories. Free Radic Biol Med. 2007;43:477-503.

37. Squadrito $\mathrm{GL}$, Pryor WA. Mapping the reaction of peroxynitrite with $\mathrm{CO}_{2}$ : energetics, reactive species, and biological implications. Chem Res Toxicol. 2002;15:885-95.

38. Albrich JM, McCarthy CA, Hurst JK. Biological reactivity of hypochlorous acid: Implications for microbicidal mechanisms of leukocyte myeloperoxidase. Proc Natl Acad Sci U S A. 1981;78:210-4.

39. Mylonas C, Kouretas D. Lipid peroxidation and tissue damage. In Vivo. 1999:13:295-309.

40. Baskurt OK, Temiz A, Meiselman HJ. Effect of superoxide anions on red blood cell rheologic properties. Free Radic Biol Med. 1998;24:102-10.

41. Hebbel RP, Eaton JW, Balasingam M, Steinberg MH. Spontaneous oxygen radical generation by sickle erythrocytes. J Clin Invest. 1982;70:1253-9.

42. Assa Y, Shany S, Gestetner B, Tencer Y, Birk Y, Bondi A. Interaction of alfalfa saponins with components of the erythrocyte membrane in hemolysis. Biochim Biophys Acta. 1973;307:83-91.

43. Winter WP. Mechanism of saponin induced red cell hemolysis. Evidence for the involvement of aquaporin CHIP28. Blood. 1994:84:1-10.

44. Yen GC, Duh PD, Tsai HL. Antioxidant and pro-oxidant properties of ascorbic acid and gallic acid. Food Chem. 2002;79:307-13.

45. Kumar S, Prahalathan P, Raja B. Antihypertensive and antioxidant potential of vanillic acid, a phenolic compound in L-NAME-induced hypertensive rats: a dose-dependence study. Redox Rep. 2011;16:208-15.

46. Kikuzaki H, Hisamoto M, Hirose K, Akiyama K, Taniguchi H. Antioxidant properties of ferulic acid and its related compounds. J Agric Food Chem. 2002;50:2161-8.

47. Zang LY, Cosma G, Gardner H, Shi X, Castranova V, Vallyathan V. Effect of antioxidant protection by p-coumaric acid on low-density lipoprotein cholesterol oxidation. Am J Physiol Cell Physiol. 2000;279:C954-60.

48. Gordon MH, Penman AR. Antioxidant activity of quercetin and myricetin in liposomes. Chem Phys Lipids. 1998;97:79-85.

49. Liu Z, Li S, Han N, Sun D, Cao Y, Yin J. Studies on the chemical constituents of the vines of Streptocaulon juventas (Lour.) Merr. Asian J Tradit Med. 2008;3:193-8.

50. Gupta R, Sharma AK, Dobhal MP, Sharma MC, Gupta RS. Antidiabetic and antioxidant potential of $\beta$-sitosterol in streptozotocin-induced experimental hyperglycemia. J Diabetes. 2011;3:29-37.

51. Chaveerach A, Aungkapattamagul S, Tanee T, Noikotr K, Sudmoon R. Genetic verification and chemical contents identification of Allamanda species (Apocynaceae). Pak J Pharm Sci. 2014;27:417-24.

52. Amarowicz R. Squalene: A natural antioxidant? Eur J Lipid Sci Technol. 2009;111:411-2.

53. Dey P, Saha MR, Chowdhuri SR, Sen A, Sarkar MP, Haldar B, et al. Assessment of anti-diabetic activity of an ethnopharmacological plant Nerium oleander through alloxan induced diabetes in mice. J Ethnopharmacol. 2014;161:128-37.

54. Dey P, Saha MR, Sen A. An overview on Drug-Induced Hepatotoxicity. Asian J Pharm Clin Res. 2013;6:1-4.

\section{Submit your next manuscript to BioMed Central and take full advantage of:}

- Convenient online submission

- Thorough peer review

- No space constraints or color figure charges

- Immediate publication on acceptance

- Inclusion in PubMed, CAS, Scopus and Google Scholar

- Research which is freely available for redistribution 